\title{
Application of Self-Ionization for Enhancing Stereochemical and Positional Effects from Arylglycosides Under Electron Ionization Conditions in an Ion Trap Mass Spectrometer
}

\author{
Marina V. Da Silva, Marie-Claude Perlat, and Jean-Claude Tabet \\ Laboratoire de Chimie Structurale Organique et Biologique, UMR 7613 CNRS, Université Pierre et Marie Curie, \\ Paris, France
}

Gianluca Giorgi, Laura Salvini, and Fabio Ponticelli

Dipartimento di Chimica and Centro Interdipartimentale di Analisi et Determinazioni Strutturali, Università di Siena, Siena, Italy

\begin{abstract}
Ion trap mass spectrometry has been used to structurally characterize and differentiate positional and stereo isomers of arylglycosides having potential antioxidant properties. The use of the self-ionization (SI) technique has allowed to evidence a strong reactivity of fragment ions produced from dissociations of the molecular ion towards the molecules introduced into the trap. Specific structural effects due to positional isomers and anomers have been also envisaged through the occurrence of bimolecular processes inside the ion trap analyzer. Under self-ionization conditions, even-electron ions are produced. The charge is retained on the sugar moiety, in agreement with its proton affinity higher than that of the substituted phenol moiety. Most of the fragmentation pathways involve elimination of acetic acid that protects the hydroxylic groups of the glycoside. SI also produces adduct ions, likely as covalent species, having higher $\mathrm{m} / \mathrm{z}$ values than the molecular ion. The reaction site is mainly the double bond present in the pyranosidic ring. Even if some fragment ions have lost the initial stereochemistry, their formation can be related to the structure of the parent neutrals introduced into the cell. Collision-induced dissociation (CID) experiments, carried out on ions formed by ionmolecule reactions, have allowed to obtain further information on gas phase ion structures. The study of mass-selected ion-molecule reactions and their kinetics have evidenced a spectacularly different reactivity of the ion at $\mathrm{m} / \mathrm{z} 111$ towards the two anomers $2 \boldsymbol{\alpha}$ and $2 \boldsymbol{\beta}$, with the latter showing a much more pronounced reactivity. The approach developed in this work revealed to be an useful tool in structural characterization, as well as in stereo and regiochemical differentiation of arylglycosides. (J Am Soc Mass Spectrom 2003, 14, 851-861) (C) 2003 American Society for Mass Spectrometry
\end{abstract}

A lot of different organic compounds can exist as isomers, such as regio, stereochemical, and positional isomers. Owing to the specific features of a given isomer, such as reactivity and biological properties, its structural characterization and differentiation is of particular importance. Different chemicophysical methods, such as nuclear magnetic resonance, circular dichroism, X-ray crystallography, and other spectroscopic methods can give useful and complementary information. One of these methods is represented by mass spectrometry (MS) [1,2] that has found more and more applications in isomer characterization and

Published online June 25, 2003

Address reprint requests to Dr. G. Giorgi, Centro Interdipartimentale di Analisi e Determinazioni Strutturali, Università di Siena, via Aldo Moro, 53100 Siena, Italy. E-mail: gianluca.giorgi@unisi.it differentiation [3, 4], some of them developed in our research groups [5-7]. MS offers several advantages over other techniques: speed of analysis, high sensitivity at low picomol level, possibility to carry out gas phase reactions, etc. A large number of investigations concerning stereochemical effects on gas phase reactions occurring in mass spectrometry experiments has been reported recently $[8,9]$.

Different mass spectrometry techniques, such as chemical ionization [10-12] and self-ionization (SI) [1316], can be successfully used. In particular, the SI mode is a suitable approach for obtaining gas phase ion species under electron ionization (EI) conditions that can be related to the stereochemistry of the parent compounds [15]. Indeed, this method allows the formation of the $\mathrm{MH}^{+}$and/or adduct ions without introducing a reagent gas. However, such processes are some- 


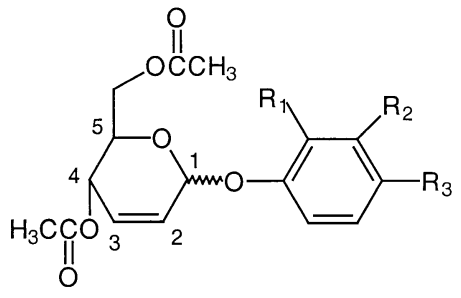

$$
\begin{array}{lll}
1 \alpha: & \mathrm{R}_{1}=\text { tert }-\mathrm{C}_{4} \mathrm{H}_{9} & \mathrm{R}_{2}=\mathrm{R}_{3}=\mathrm{H} \\
2 \alpha, \beta: & \mathrm{R}_{2}=\text { tert }-\mathrm{C}_{4} \mathrm{H}_{9} & \mathrm{R}_{1}=\mathrm{R}_{3}=\mathrm{H} \\
3 \alpha: & \mathrm{R}_{3}=\text { tert }-\mathrm{C}_{4} \mathrm{H}_{9} & \mathrm{R}_{1}=\mathrm{R}_{2}=\mathrm{H}
\end{array}
$$

Scheme 1. Chemical structures of the compounds (MW $362 \mathrm{u}$ ) under investigation.

what weakly efficient into an EI source of an ion beam mass spectrometer. Nevertheless, the use of a temporal mass spectrometer, such as an ion trap [17-19], causes the self-ionization analytical technique to be particularly effective. This is because the reagent ions can be selectively stored for a relatively large reaction time that can be varied and optimized so as to enhance the yield of ion-molecule reactions.

A large class of isomers is constituted by carbohydrates and glycosides [20-22]. Depending upon their chemical structures, they show various chemico-physical properties and can play a key role in a lot of biological processes. Their characterization is particularly complex due to wide possibilities of linkage between the different moieties, stereochemistry of each monosaccharide unit, and branching of the various units. In the last few years, there has been a growing interest in the discovering, characterization, and isomeric differentiation of new glycosides having enhanced, selective, and distinctive properties. A lot of effective mass spectrometric approaches have been developed by different research groups [23-26].

1,4-Disubstituted phenol derivatives can show antioxidant properties and can be used as food preservatives [27] and protective agents against oxidative stress processes in vivo [28]. Chemical modifications of their skeleton allow to enhance and modulate their properties. In particular, by introducing a glycosidic moiety it is possible to obtain new synthetic compounds in which a fine-tuning of their antioxidant activity can be achieved.

In a research project aimed at obtaining new antioxidant agents, we recently synthesized new $O$-glycopyranosyl arenes (1-3, Scheme 1) [29]. They are analogous to 2(3)-tert-butyl-4-hydroxyanisole with increased water solubility due to the presence of the sugar moiety.

Compounds $1-3$ (MW $=362 \mathrm{u}$ ) are positional isomers, differing in the position of the tert-butyl group. About the stereochemistry at $C(1)$, they are generally $\alpha$-anomers, while for 2 both the $\alpha$ - and $\beta$-anomers have been studied. The gas phase reactivity of these positional isomeric and anomeric arylglycosides has been

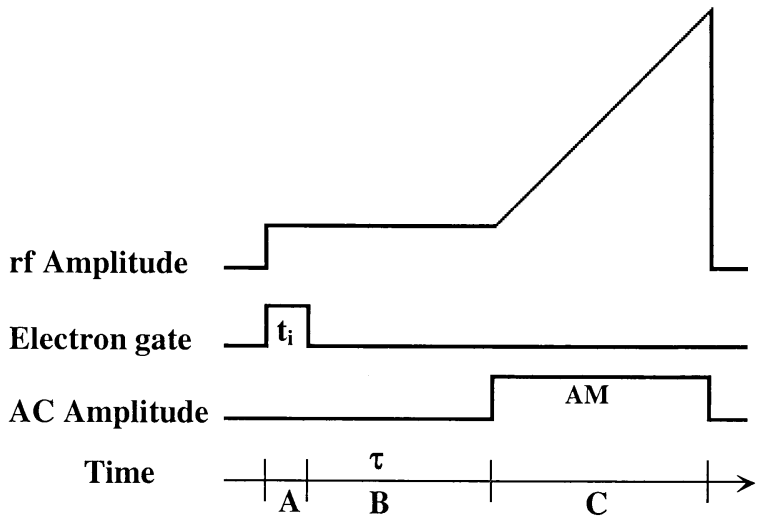

Scheme 2. Scan function used for self-ionization experiments from unselected EI fragment ions in an ion trap, (A) ionization pulse; (B) reaction time $\tau$; (C) period of the axial modulation application for the ion analysis after reaction.

explored by using the self-ionization, selective selfionization modes, and collision-induced dissociation (CID) experiments.

\section{Experimental}

Compounds 1-3 have been prepared according to synthetic approaches reported in references [29, 30]. A Varian Star 3400 CX (Varian, Walnut Creek, CA) gas chromatograph was used for introducing the sample solutions $\left(2.0 \mu \mathrm{L}, 1.0 \pm 0.1 \times 10^{-5} \mathrm{M}\right.$ in ethyl acetate $)$ in the gas phase. A The solutions of all the isomers were equimolar. DB-5 (30 m $\times 0.25 \mathrm{~mm}$ i.d., Supelco) gas chromatograph column was used in the splitless mode. The oven temperature was programmed from $60^{\circ} \mathrm{C}(1$ min) to $150{ }^{\circ} \mathrm{C}$ at $30{ }^{\circ} \mathrm{C} / \mathrm{min}$ and then ramped to $250{ }^{\circ} \mathrm{C}$ at $20^{\circ} \mathrm{C} / \mathrm{min}$. The transfer line was maintained at 265 ${ }^{\circ} \mathrm{C}$ and the injector at $220^{\circ} \mathrm{C}$. Mass spectrometry experiments have been carried out by using a Varian Saturn III ion trap (Varian) that operates with He buffer gas at $\sim 13.33 \times 10^{-2} \mathrm{~Pa}$ (i.e., $\sim 10^{-3}$ torr). The package software QISMS (version 1.0, written by R. March and G. Well distributed by Varian) [31] was used for customizing the scan functions. The low $\mathrm{m} / \mathrm{z}$ ratio cutoff (LMCO) as $30 \mathrm{Th}$ was chosen and corresponds to $\mathrm{V}_{o-p}=$ $307 \mathrm{~V}$ of the drive rf potential. EI experiments were performed by using conventional scan functions proposed by the manufacturer without application of the segmentation function.

Self-ionization experiments were carried out according to the scan function reported in Scheme 2. The initial time (a), in which the ionization occurs, is followed by a reaction time $\tau$, generally, in the range 325-650 ms (b), so to allow ion-molecule reactions. The analytical scan, performed during the period (c), by applying an axial modulation (AM), completes the cycle. The full $\mathrm{m} / \mathrm{z}$ range was scanned without application of segmentation for self-ionization experiments [31]. Adduct ions formed under self-ionization conditions were isolated and underwent CID experiments. 


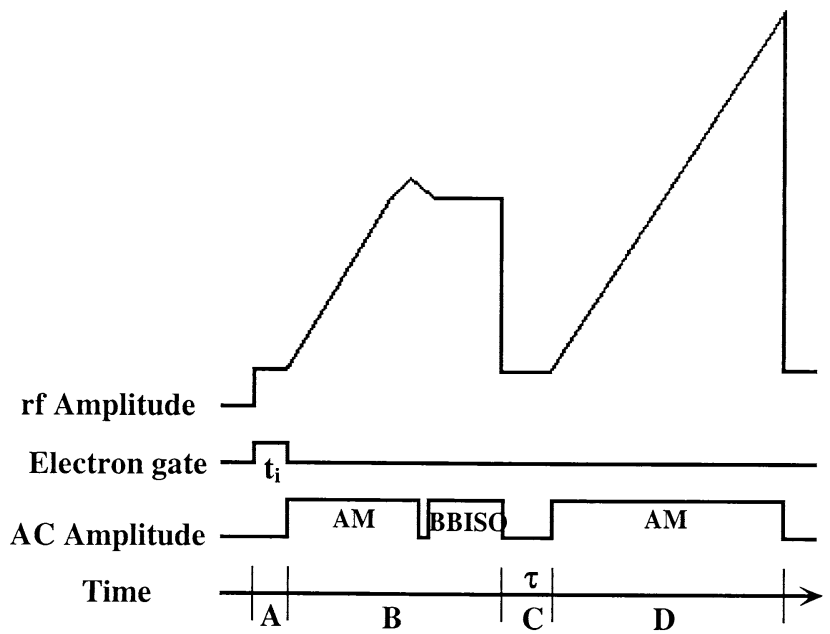

Scheme 3. Scan function used for studying EI fragment ion reactivity in an ion trap, (A) ionization pulse; (B) isolation of the mass-selected ion: application of axial modulation (AM) for ejection of ions of lower $\mathrm{m} / \mathrm{z}$ ratios, followed by a broadband isolation step (BBISO) for ejection of ions with higher $\mathrm{m} / \mathrm{z}$ ratios than that of the selected ion; (C) reaction time $\tau$ for producing ion-molecule reactions between the mass selected ion and the neutrals; (D) period of the axial modulation application for the ion analysis after gas phase reaction.

Selective self-ionization experiments consisted in the selection of the reagent ions prior to the ion-molecule reaction step. This is achieved by (1) raising the rf amplitude in order to eject ions having $m / z$ values lower than that of the isolated ion, and (2) applying a multifrequency waveform broadband isolation step (BBISO), to eject ions having higher $m / z$ values. The introduction of variable reaction times $\tau$ allows the occurrence of selected ion-molecule reactions (Scheme 3).

Replicated measurements showed that the reproducibility of the relative peak abundances in the SI and CID spectra was within $10 \%$.

\section{Results and Discussion}

\section{Self-Ionization Mass Spectra of Stereo and Regio} Isomeric Compounds: Structural Effects Due to the Intact Neutrals Reacting with EI Fragment Ions

The first approach that we have used for studying the gas phase ion chemistry of Compounds $1 \boldsymbol{\alpha}, 2 \boldsymbol{\alpha}, 2 \boldsymbol{\beta}$ and $3 \boldsymbol{\alpha}$ have been electron ionization by using an ion trap.
The resulting EI mass spectra are very similar to each other for all the compounds, under the experimental error (Table 1). The molecular ions are undetectable and most of the total ion current is carried out by four main ionic species at $m / z 213,153,111$, and 43. According to the Domon and Costello nomenclature [26], the $m / z 213$ ion is a B-type oxonium ion that results from the cleavage of the oxygen linkage between the two rings with charge retention at the glycosyl moiety and a tert-butylphenoxy radical release. This B-type ion loses a neutral $\mathrm{CH}_{3} \mathrm{COOH}$ via 1,2-elimination to form an abundant trienic ion at $m / z$ 153. The loss of $\mathrm{CH}_{2} \mathrm{CO}$ from the ionic species at $m / z 153$ yields the ion at $m / z 111$. The ion at $m / z 43$ is attributable to $\left[\mathrm{CH}_{3} \mathrm{CO}\right]^{+}$. The mechanistic pathway, reported in Scheme 4 , has been confirmed by MS/MS daughter ion experiments carried out by selecting each of the ions at $m / z 213,153$, and 111 .

Owing to the prevention of an isomeric differentiation by the electron ionization mass spectra, we studied the gas phase behavior and reactivity of these isomers under self-ionization (Table 2). This technique was first applied to the characterization and stereochemical differentiation of the anomers $2 \boldsymbol{\alpha}$ and $\boldsymbol{2} \boldsymbol{\beta}$ (Figure 1). Under SI conditions, after a residence time of $325 \mathrm{~ms}$ in which gas phase reactions can occur, the molecular ion $(\mathrm{m} / \mathrm{z}$ 362) does not appear in the EI mass spectrum. Similar to that observed under EI conditions, two main ions, at $m / z 213$ and 153, are produced.

In EI mass spectra, diagnostic ions at $m / z 43$ and $m / z$ 111 are very abundant $(m / z 43)$, or constitute the base peak $(m / z 111)$ for both $2 \boldsymbol{\alpha}$ and $2 \boldsymbol{\beta}$ stereoisomers (Table $1)$. On the other hand, these ions are absent $(m / z 43)$ or extremely scarce $(m / z 111)$ under SI conditions (Figure 1 ). The ion at $m / z 153$ is slightly decreased in respect to the EI conditions for the two meta anomers, while the opposite trend is observed for $\mathbf{1} \boldsymbol{\alpha}$ and $\mathbf{3} \boldsymbol{\alpha}$ (Table 2).

Surprisingly, the disappearance of the ions at $m / z 43$ and 111 and of that of the less intense ion at $m / z 153$ does not yield an increased intensity of product ions with $m / z$ values higher than the intact arylglycoside (i.e., $m / z 515,455$, and 395). In fact only the ion at $m / z$ 213 seems to be strongly enhanced. The position in the stability diagram of the high mass product ions does not allow similar storage efficiencies to that characterizing the low mass EI fragment ions (i.e., $\mathrm{m} / \mathrm{z} 153$ and 213). This is because the high mass product ions are stored in a pseudo-potential wall much lower than that

Table 1. Electron ionization mass spectral data for isomers $1 \boldsymbol{\alpha}, \mathbf{2} \boldsymbol{\alpha}, \mathbf{2} \boldsymbol{\beta}$, and $\mathbf{3} \boldsymbol{\alpha}$. The $m / z$ values and the percentage of the total ion current $^{\mathrm{a}}$ of the most abundant ions are reported

\begin{tabular}{|c|c|c|c|c|c|c|c|}
\hline \multirow[b]{2}{*}{ Isomers } & \multicolumn{4}{|c|}{ lons (Th) } & \multicolumn{3}{|c|}{ Characteristic ion abundance ratios } \\
\hline & 43 & 111 & 153 & 213 & $153 / 213$ & $111 / 153$ & $111 / 213$ \\
\hline $1 \alpha$ & 14.8 & 34.1 & 20.6 & 5.1 & 4.0 & 1.7 & 6.7 \\
\hline $2 \alpha$ & 14.3 & 33.5 & 20.6 & 5.5 & 3.7 & 1.6 & 6.1 \\
\hline $2 \boldsymbol{\beta}$ & 13.6 & 33.7 & 20.2 & 5.4 & 3.7 & 1.7 & 6.2 \\
\hline $3 \alpha$ & 13.8 & 33.6 & 20.1 & 5.4 & 3.7 & 1.7 & 6.2 \\
\hline
\end{tabular}

${ }^{a}$ Calculated as: $100 \times$ ion intensity $/ \Sigma$ intensity (all sample ions). 


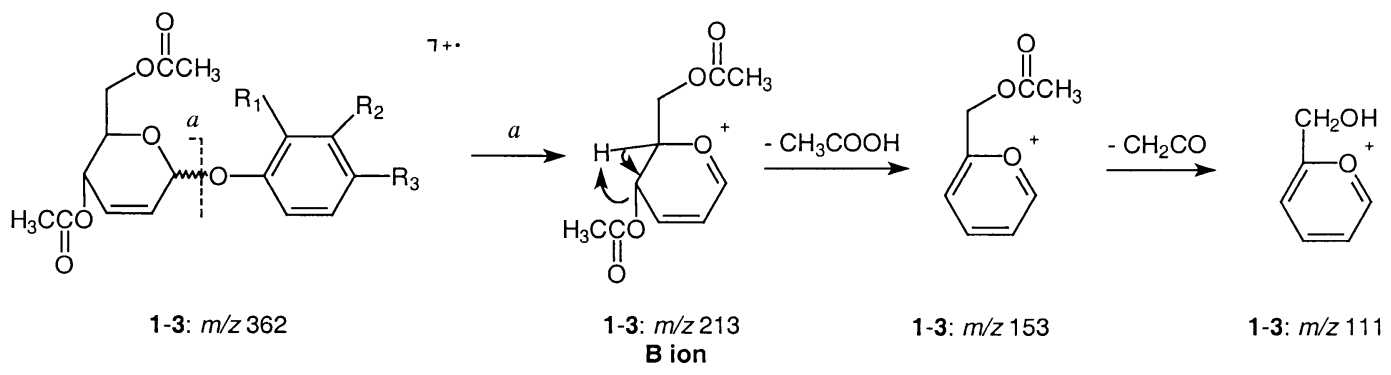

Scheme 4. Consecutive fragmentations of the odd-electron molecular ion occurring under electron ionization conditions.

of the low mass ions. However, this reason cannot explain entirely the low abundance of the adduct ions. If one assumes that they yield the species at $\mathrm{m} / \mathrm{z} 213$ as the final step of their dissociation, it results that this ionic species is produced by ion-molecule reactions between EI fragment ions and neutrals. Thus, the ion at $\mathrm{m} / \mathrm{z} 213$ does not have the same origin that is produced by EI and its relative yield is dependent upon stereochemical and structural effects of the intact isomeric molecules.

As under SI conditions all the ions are at odd $\mathrm{m} / \mathrm{z}$ values, they are even-electron species. The positive charge is retained mainly on the sugar, in agreement with its proton affinity relatively higher than that of the substituted phenol moiety [32]. Fragment ions containing the aryl moiety are not detectable. Minor, but significant, additional ions at $\mathrm{m} / \mathrm{z} 303$ and 323 are observed with large reproducibility, although they are characterized by low abundances.

In addition, self-ionization produces adduct species, likely as covalent forms, having higher $\mathrm{m} / \mathrm{z}$ values than the parent molecular ion. The most abundant adduct ions are at $m / z 515,455$, and 395 . Their relative abundances are two-fold higher for isomer $2 \boldsymbol{\alpha}$ than $\mathbf{2} \boldsymbol{\beta}$ (Figure 1, insets), thus reflecting the different stereochemistry of the two anomers. The $\mathrm{m} / \mathrm{z} 515$ ion formally corresponds to $\left[\mathrm{M}+\mathrm{C}_{5} \mathrm{H}_{4} \mathrm{OCH}_{2} \mathrm{OC}(\mathrm{O}) \mathrm{CH}_{3}\right]^{+}$. It is produced by electrophilic addition of the $\left[\mathrm{C}_{5} \mathrm{H}_{4} \mathrm{OCH}_{2} \mathrm{OC}(\mathrm{O}) \mathrm{CH}_{3}\right]^{+}$fragment ion $(\mathrm{m} / \mathrm{z}$ 153) to the double bond of the glycosidic ring of the intact molecules at $\mathrm{C}(2)$ or $\mathrm{C}(3)$ position (Scheme 5, vide infra). Mass-isolation of ions at $\mathrm{m} / \mathrm{z} 153$ followed by a delay time, to allow the occurrence of ion-molecule reactions, shows the formation, among others, of the ion at $\mathrm{m} / \mathrm{z}$
515, thus confirming this pathway (vide infra). By loss of one or two molecules of acetic acid from the adduct ion at $m / z 515$, the species at $m / z 455$ and 395 are formed through a proton migration from a vicinal site to the charge site. These losses can occur independently by the electrophilic attack site, i.e., C(2) or C(3).

The self-ionization technique was also used for regioisomeric characterization and differentiation of compounds having the tert-butyl group in different positions of the phenyl ring. Concerning the positional isomers $1 \boldsymbol{\alpha}, 2 \boldsymbol{\alpha}$, and $3 \boldsymbol{\alpha}$, characterized by the same anomeric linkage, their SI mass spectra display a similar reactivity, yielding product ions having the same $\mathrm{m} / \mathrm{z}$ values. One of the most significant differentiation is due to the much lower relative intensity of the ion at $\mathrm{m} / \mathrm{z} 515$ in the SI mass spectra of $\mathbf{1} \boldsymbol{\alpha}$ and $\mathbf{3} \boldsymbol{\alpha}$ in comparison with that shown by the meta isomer $\mathbf{2} \boldsymbol{\alpha}$ (Table 2). Related to this there is the observation that the abundance of the fragment ion at $m / z 153$ is higher for the $1 \boldsymbol{\alpha}$ and $3 \boldsymbol{\alpha}$ isomers than for $2 \boldsymbol{\alpha}$. The increase of the reaction time from 325 to $600 \mathrm{~ms}$ does not change significantly this trend.

The stereo- and regio-chemistry are lost in the fragment ions at $\mathrm{m} / \mathrm{z} 213$ and 153 (Scheme 4). Even if the former constitutes the base peak in the SI spectra produced by all the isomers, significant differences in its abundance, expressed as the percentage of the total ion current, occur among the isomers (Table 2). Also, the abundance of the ion at $\mathrm{m} / \mathrm{z} 153$ shows deep differences among the four isomers. By assuming similar internal energy distribution, these differences might be related to the energetics (activation energy or energy threshold) of breaking the glycosidic bond that is dependant upon the structure of the parent compound,

Table 2. Percentage of the total ion current ${ }^{\mathrm{a}}$ of the main ions produced from $\mathbf{1} \boldsymbol{\alpha}, \mathbf{2} \boldsymbol{\alpha}, \mathbf{2} \boldsymbol{\beta}$, and $\mathbf{3} \boldsymbol{\alpha}$ under SI conditions (reaction time $=325 \mathrm{~ms}$ )

\begin{tabular}{|c|c|c|c|c|c|c|c|c|c|}
\hline \multirow[b]{2}{*}{ Isomers } & \multicolumn{5}{|c|}{ lons (Th) } & \multicolumn{4}{|c|}{ Characteristic ion abundance ratios } \\
\hline & 515 & 455 & 395 & 213 & 153 & $455 / 515$ & $455 / 395$ & $395 / 515$ & $153 / 515$ \\
\hline $1 \alpha$ & 0.1 & 1.3 & 0.4 & 43.0 & 33.0 & 9.4 & 3.5 & 2.7 & 233.3 \\
\hline $2 \alpha$ & 1.1 & 4.6 & 1.8 & 59.8 & 15.4 & 4.1 & 2.6 & 1.6 & 13.8 \\
\hline $2 \boldsymbol{\beta}$ & 0.8 & 3.0 & 1.4 & 66.0 & 12.4 & 4.0 & 2.2 & 1.8 & 16.4 \\
\hline $3 \alpha$ & 0.4 & 3.5 & 1.9 & 51.4 & 25.6 & 9.6 & 1.8 & 5.3 & 69.5 \\
\hline
\end{tabular}

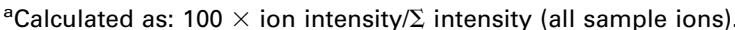



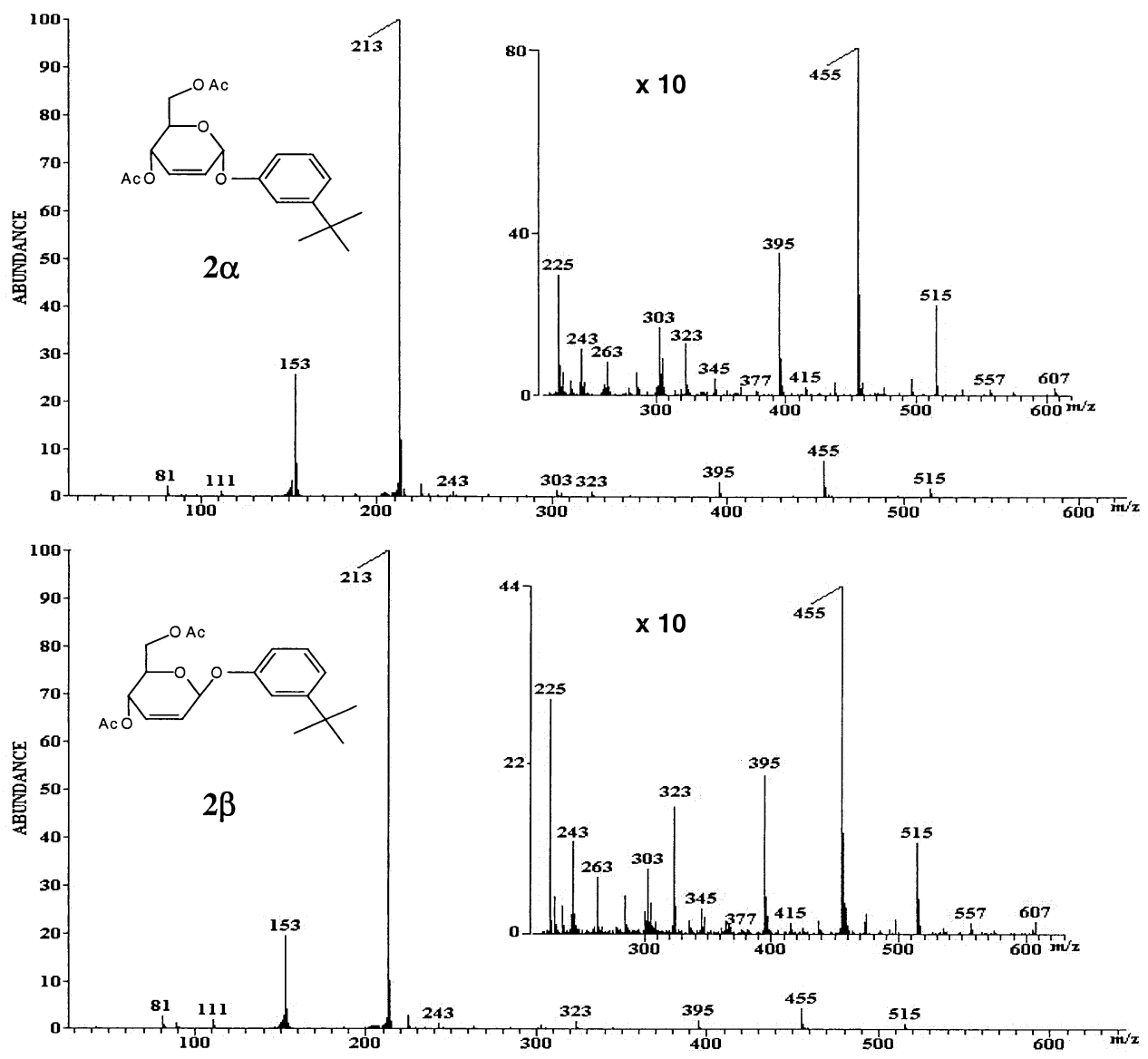

Figure 1. Self-ionization mass spectra $(\tau=325 \mathrm{~ms}, \mathrm{LMCO}=30 \mathrm{Th})$ of the $\mathbf{2} \boldsymbol{\alpha}$ (top) and $\mathbf{2} \boldsymbol{\beta}$ (bottom) anomers $(\mathrm{MW}=362 \mathrm{u}$ ). The high $\mathrm{m} / \mathrm{z}$ scale with relative intensities multiplied by a factor 10 is shown in the insets.

and influences the unimolecular rate constant of formation of the fragment ions. On the other hand, these factors also occur under electron ionization conditions, but in such a case an isomeric differentiation based on the abundances of the ions at $\mathrm{m} / \mathrm{z} 213$ and 153 is not possible (Table 1). This suggests that it is likely that the large internal energy carried out by $\mathrm{M}^{+} \bullet$ generated in EI may explain the absence of structural effects as well as the increased abundance of the ions at $\mathrm{m} / \mathrm{z} 111$ and 43 . It follows that the significant variation of abundances of these ions, observed under SI conditions for isomers $\mathbf{1} \boldsymbol{\alpha}-\mathbf{3} \boldsymbol{\alpha}$, can be mainly related to their reactivity and/or their production (i.e., that of the $\mathrm{m} / \mathrm{z} 213$ ion) from lower $\mathrm{m} / \mathrm{z}$ fragment ions which disappear according to different bimolecular rate constants with the parent neutrals in which the initial distinctive structure is preserved. In fact, large variations in the abundance of the ion at $\mathrm{m} / \mathrm{z}$ 153 are related to those of the ion species at $\mathrm{m} / \mathrm{z} 515$, formed by electrophilic addition of the ion at $\mathrm{m} / \mathrm{z} 153$ to the molecular neutral (vide infra).

In order to obtain further information on adduct ion structures, CID experiments have been carried out on the most abundant ones formed by SI processes.
Structure Elucidation of the Adduct Ion [M+ $153]^{+}$(m/z 515) Produced by the $2 \boldsymbol{\alpha}$ and $2 \boldsymbol{\beta}$ Anomers Owing to Self-Ionization

The ionic species at $m / z 515$ has sufficient abundance to allow ion selection and CID only for the $2 \boldsymbol{\alpha}$ and $\mathbf{2 \beta}$ anomers, while for all the other isomers, the CID spectra of the ion at $\mathrm{m} / \mathrm{z} 455$ have been studied (vide infra). Low energy CID spectra, obtained with different tickle excitation duration $(\tau)$, of the ions at $\mathrm{m} / \mathrm{z} 515$ formed from the $2 \boldsymbol{\alpha}$ and $\mathbf{2} \boldsymbol{\beta}$ anomers under SI conditions are reported in Figure 2.

When an excitation time of $3 \mathrm{~ms}$ is applied, the product ions can be grouped into two main series (Figure 2, top row). The first contains ions at $\mathrm{m} / \mathrm{z} 455$, 395, and 335, much more abundant for $2 \boldsymbol{\alpha}$ than for $\mathbf{2} \boldsymbol{\beta}$, attributable to consecutive losses of acetic acid molecules from the species at $m / z 515$.

This behavior may be explained by considering that for the three $\alpha$ isomers the electrophilic attack of the species $\left[\mathrm{C}_{5} \mathrm{H}_{4} \mathrm{OCH}_{2} \mathrm{OC}(\mathrm{O}) \mathrm{CH}_{3}\right]^{+}$(indicated as $\mathrm{G}^{+}$in Scheme 5) to the neutral occurs selectively at the opposite side of the anomeric $\mathrm{C}(1)$ of the sugar. In fact, owing 

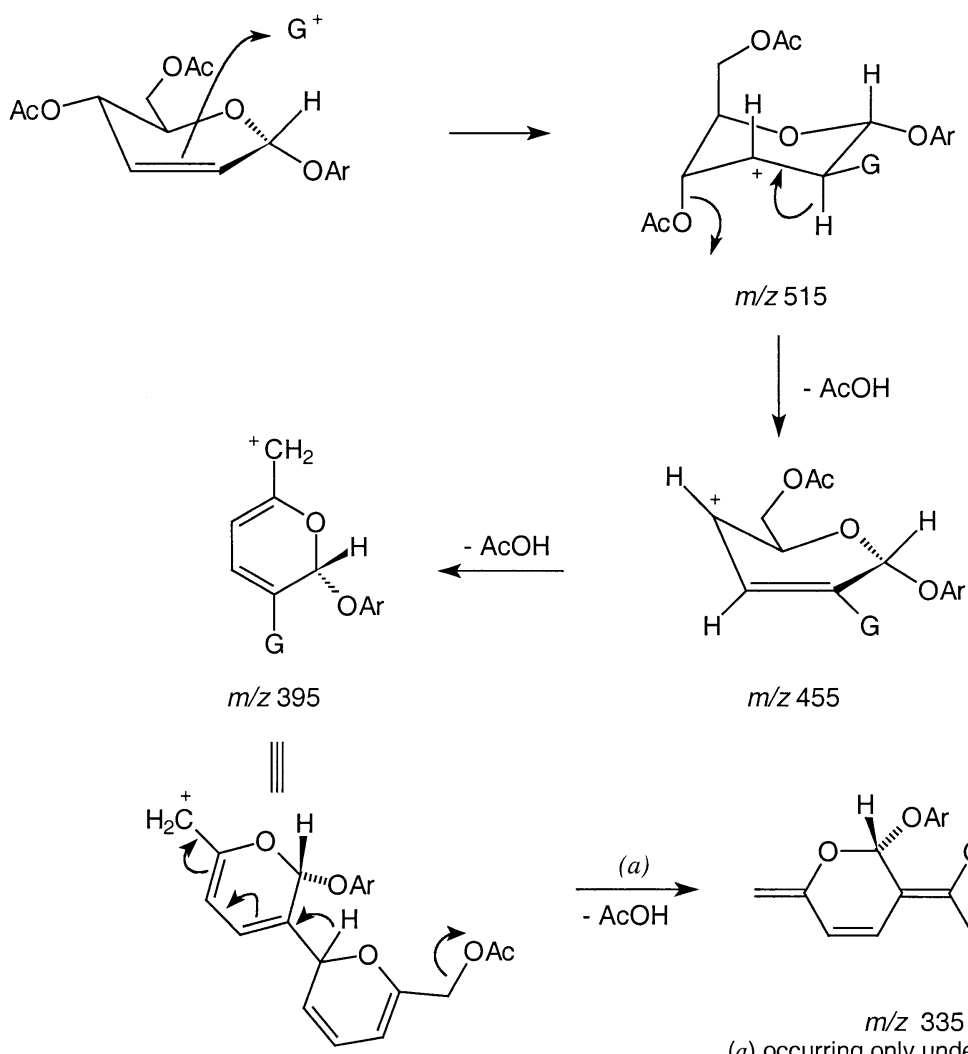

$m / z 455$

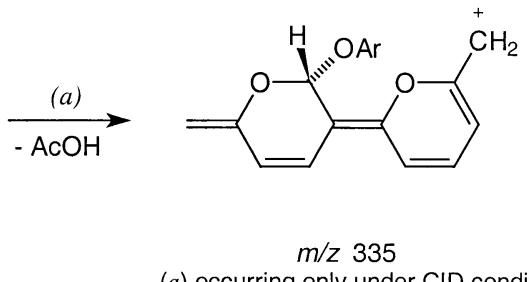

(a) occurring only under CID condition:

$\mathrm{Ar}=$ tert-butylphenol

$\mathrm{G}=\left[\mathrm{C}_{5} \mathrm{H}_{4} \mathrm{OCH} \mathrm{H}_{2} \mathrm{OC}(\mathrm{O}) \mathrm{CH}_{3}\right]^{+}$

Scheme 5. Proposed electrophilic addition of the fragment ion at $m / z 153$ to the parent neutrals 1-3 (MW $362 \mathrm{u}$ ) yielding ions at $\mathrm{m} / z$ 515. The $\beta$-side attack at atom $\mathrm{C}(2)$ of the double bond of the glycosidic ring is shown. It is followed by consecutive acetic acid losses via syn 1-3 eliminations and long distance $\mathrm{H}$ transfer.

to the steric hindrance of the aromatic group a trans stereochemical approach is favored. It follows that in the resulting ion at $m / z 515$ both the aromatic moiety and the new introduced group are in trans configuration. On the other hand, as shown in Scheme 5, both the hydrogen atom at $C(2)$ and acetate group at $C(4)$ position are on the same ring side (i.e., $\alpha$-configuration). It follows that this $\mathrm{AcO} / \mathrm{H}$ cis geometry favors the acetic acid loss that is activated by the neighboring positive charge. This process yields the ion at $m / z 455$ which in turn can dissociate by one or two consecutive losses of acetic acid molecules. Product ions at $m / z 395$ and 335 are produced, respectively, with the latter species being stabilized by charge delocalization. This confirms that the ion at $\mathrm{m} / \mathrm{z} 515$ contains at least three acetate substituents.

With the exception of the ion at $m / z 335$, ionic species at $m / z 455$ and 395 are also detectable in the SI mass spectra of both the $2 \boldsymbol{\alpha}$ and $\mathbf{2} \boldsymbol{\beta}$ anomers (Figure 1).

The second series of product ions present in the CID spectra of the ion at $\mathrm{m} / \mathrm{z} 515$ obtained from isomers $2 \boldsymbol{\alpha}$ and $2 \boldsymbol{\beta}$ begins with the ion at $\mathrm{m} / z 497$ (Scheme 6). It is due to the loss of water from the species at $m / z 515$, or eventually, to the loss of $60 \mathrm{u}$ from the ion $\mathrm{m} / \mathrm{z} 557$, a higher $m / z$ value than the selected parent ion. This latter mechanism can be ruled out since the ion at $\mathrm{m} / \mathrm{z} 557$ cannot be resonantly excited by the applied tickle voltage that is specific for the precursor ion at $\mathrm{m} / \mathrm{z} 515$. Thus, the second series of fragment ions must be initiated by the loss of water from the species at $m / z 515$ followed by consecutive losses of acetic acid rather than the direct elimination of acetic acid from the adduct $m / z$ 547 ion, especially favored by the $2 \boldsymbol{\beta}$ anomer.

Further decompositions of the ion at $m / z 497$ consist in eliminations of one or two molecules of $\mathrm{CH}_{3} \mathrm{COOH}$, producing the species at $\mathrm{m} / \mathrm{z} 437$ and 377, respectively (Scheme 6), although the last one should be formed by a particularly complex mechanism not elucidated yet. Some crossing between the two series, such as the reaction pathways $m / z 455 \rightarrow m / z 437$ and $m / z 395 \rightarrow m / z$ 377 , involving the loss of a water molecule, cannot be ruled out. The water loss, reasonably occurring from the sugar moiety, strongly suggests an open-ring structure for the glycopyranosyl moiety of the ion at $\mathrm{m} / \mathrm{z} 515$ (Scheme 6).

Species at higher $\mathrm{m} / \mathrm{z}$ values than that of the selected 

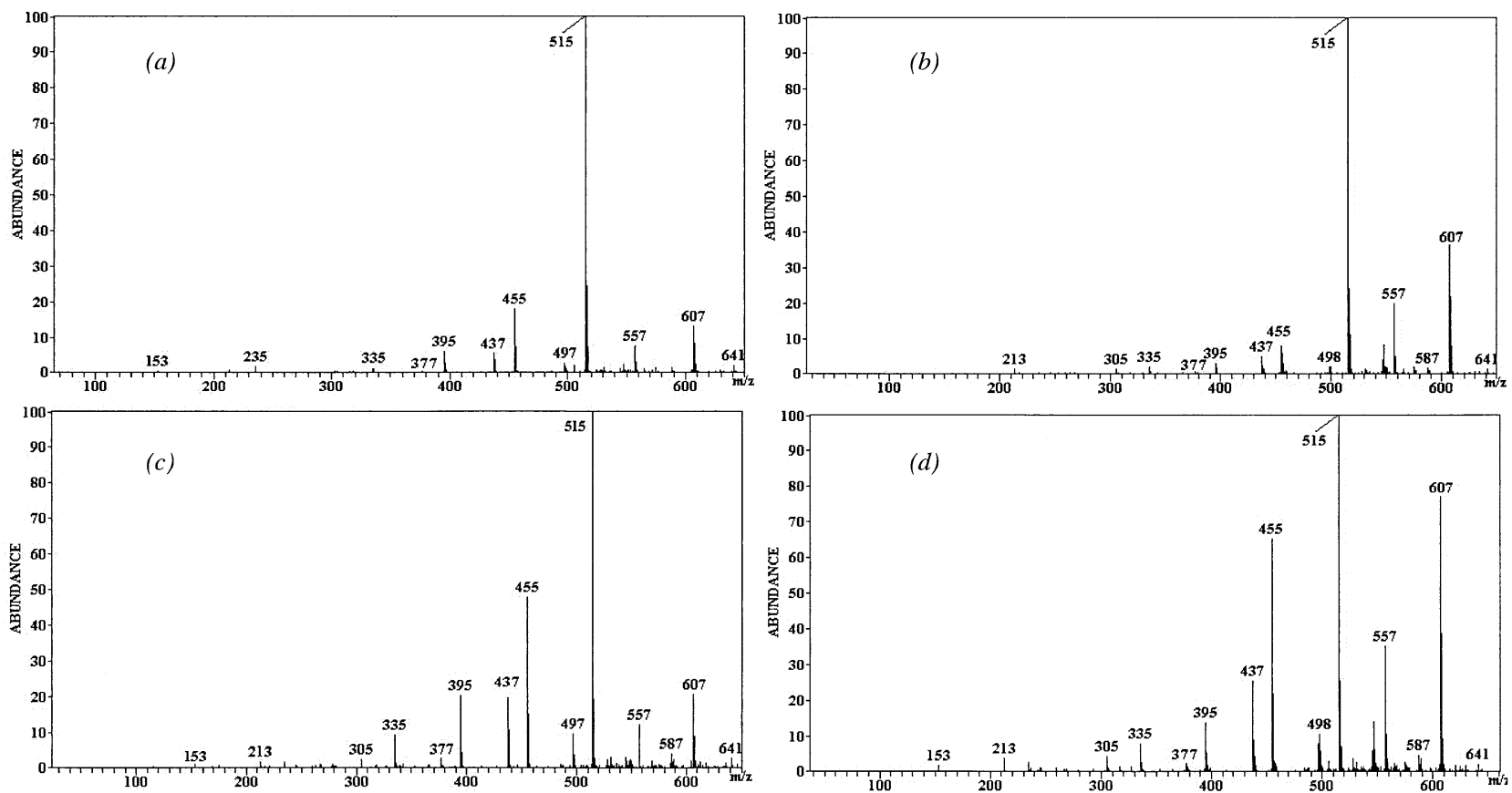

Figure 2. Low energy CID spectra of the covalent adduct ions at $\mathrm{m} / \mathrm{z} 515$ prepared under SI conditions from unselected EI fragment ions. The samples were introduced into the ion trap through the GC interface. Top row: $\tau=3 \mathrm{~ms}$; (a) $2 \boldsymbol{\alpha}$ and (b) $2 \boldsymbol{\beta}$ anomers. Bottom row: $\tau=6 \mathrm{~ms}$; (c) $2 \boldsymbol{\alpha}$ and (d) $2 \boldsymbol{\beta}$ anomers.

ion $(\mathrm{m} / \mathrm{z} 515)$ are also formed. They are at $\mathrm{m} / \mathrm{z} 547,557$, 587 , and 607. A priori, two main types of ion-molecule reactions could be envisaged to explain their formation. One reaction might occur between fragment ions produced by the decomposition of the selected ion and the intact neutral arylglycoside introduced into the analyzer via the GC column. The second type of reactions might involve the neutral fragments, sufficiently stored in the trap and the selected ion at $\mathrm{m} / \mathrm{z} 515$. The former assumption can be ruled out since, during the ion isolation step of the fragment species at $\mathrm{m} / \mathrm{z} 515$, these high mass ions are also produced. On the other hand, this suggests that the latter possibility is more reasonable. In fact, by increasing the time preceding the selected ion excitation, an enhancement of the relative abundance of these new ionic species occurs, while new fragment ions are not detected. The neutrals responsible for these ion-molecule reactions could be either the intact arylglycoside or the fragment neutrals that can be produced by pyrolysis or by ion fragmentation prior to the selection step. As an example, the nucleophilic attachment by ketene (i.e., $\mathrm{H}_{2} \mathrm{C}=\mathrm{C}=\mathrm{O}$ ) to the ion at $\mathrm{m} / \mathrm{z}$ 515 yields the product ion at $\mathrm{m} / \mathrm{z} 557$.

Alternatively, reaction between the intact neutral arylglycoside and the charged species at $\mathrm{m} / \mathrm{z} 515 \mathrm{might}$ produce a reactive intermediate ion at $\mathrm{m} / \mathrm{z} 877$, as a transient ion. Its decomposition by loss of the aromatic group should be favored especially from the $\mathbf{2} \boldsymbol{\beta}$ anomer. Migration of the proton at $C(4)$ is reasonably involved as it is assisted by the double bond migration to give rise to formation of the ion at $m / z 727$. In turn, this might decompose by a double $60 \mathrm{u}$ neutral loss to generate the species at $\mathrm{m} / \mathrm{z} 607$ (Scheme 7). It is noteworthy that the ions at $m / z 877$ and 727 , which are precursors of the ion at $\mathrm{m} / \mathrm{z} 607$, cannot be detected owing to ejection from the ion trap because they are beyond the $\mathrm{m} / \mathrm{z}$ scale, although they can be stored into the trap towards low $\mathrm{q}_{\mathrm{z}}$ values. This takes place under a weak pseudo-potential Dehmelt wall from which many ions may escape the storage cell; also, its ejection requires too high drive RF voltage (higher than 7000 $\mathrm{V}_{p-p}$ ) impossible to be produced in our instrument. On the other hand, the increase of the LMCO values for the storage of selected parent ions cannot be a solution for the same reason. The possibility of ejecting ions at $q_{z}$ values lower than 0.908 is the only mode useful for reaching higher mass range, but ion ejection at nonlinear resonant $\beta_{\mathrm{z}}$ values $\left(\beta_{\mathrm{z}}<1\right)$ is not available in our instrument.

Based upon the formation of these large precursor cations, the higher efficiency of the formation of the ion at $m / z$ 607, observed for the $\mathbf{2} \boldsymbol{\beta}$ anomer, can be explained by considering the particular stereochemistry of both the AcO- and $\left(\mathrm{H}_{3} \mathrm{C}\right)_{3} \mathrm{C}-\mathrm{C}_{6} \mathrm{H}_{4} \mathrm{O}$ - substituents directly linked to the heterocyclic skeleton. Indeed, such a relative stereochemistry permits to enhance the formation of the ion at $\mathrm{m} / \mathrm{z} 607$ from dissociation of larger precursors.

An increase from 3 to $6 \mathrm{~ms}$ of the excitation time of the ion at $m / z 515$ does not enhance the anomer differentiation. However, as expected, an increase of the relative abundances of all the fragment ions belonging 


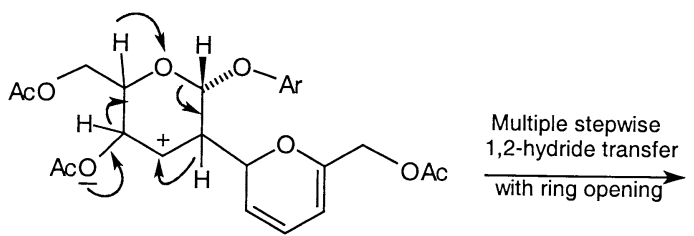

$m / z 515$<smiles>CCOC(C)=O</smiles>

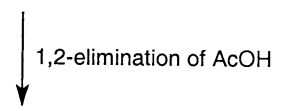<smiles>C=C/C(=C\C(=C/O[Al])c1cccc(COC(C)=O)[o+]1)OC(C)=O</smiles>

$m / z 437$

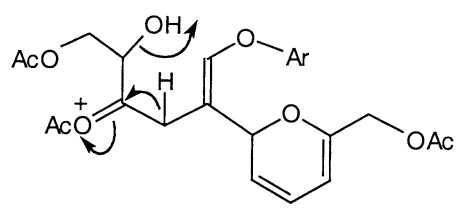

$m / z 515$

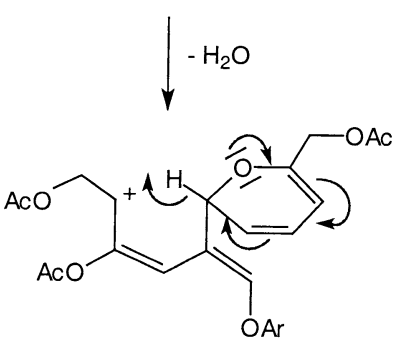

$m / z 497$

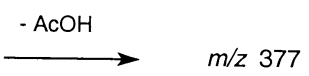

$\operatorname{Ar}=$ tert-butylphenol

Scheme 6. Ring-opening process of the adduct ion at $\mathrm{m} / \mathrm{z} 515$ occurring under CID conditions. It yields water loss followed by consecutive acetic acid eliminations.

to the two series it is observed: (1) $\mathrm{m} / \mathrm{z} 455,395$, and 335, and (2) $m / z 497,437$, and 377 , as well as the series of the adduct ions at $m / z 547,557$, and 607, which are changed to a lesser extent than the fragment ions.

\section{CID Spectra of the Ion $[M+153-60]^{+}(\mathrm{m} / \mathrm{z}$ 455) Generated Under SI Conditions}

The loss of acetic acid from the adduct ion at $\mathrm{m} / \mathrm{z} 515$ yields the species at $\mathrm{m} / \mathrm{z} 455$ in which two acetate groups are preserved. Its CID spectra (Table 3 ) display fragment ions due to (1) the loss of one or two acetic acid molecules (i.e., $m / z 395$ and 335), and (2) consecutive eliminations of water molecules, yielding fragment ions at $m / z$ 437, 377, and 317.

As in the case of the CID processes of the species at $\mathrm{m} / \mathrm{z} 515$, in the case of that at $\mathrm{m} / \mathrm{z} 455$, also, adduct ions are observed at $m / z 497,515,557,575$, and 607 . Reasonable pathways for their formation have been discussed in the latter section. Interestingly, in the case of the species at $m / z 455$ some findings have to be pointed out: (1) The adduct ions at $\mathrm{m} / \mathrm{z}$ values higher than $\mathrm{m} / \mathrm{z} 455$ are relatively low for the ortho $1 \boldsymbol{\alpha}$ and para $3 \boldsymbol{\alpha}$ isomers compared to both the meta $2 \boldsymbol{\alpha}, \mathbf{2} \boldsymbol{\beta}$ anomers; (2) addi-

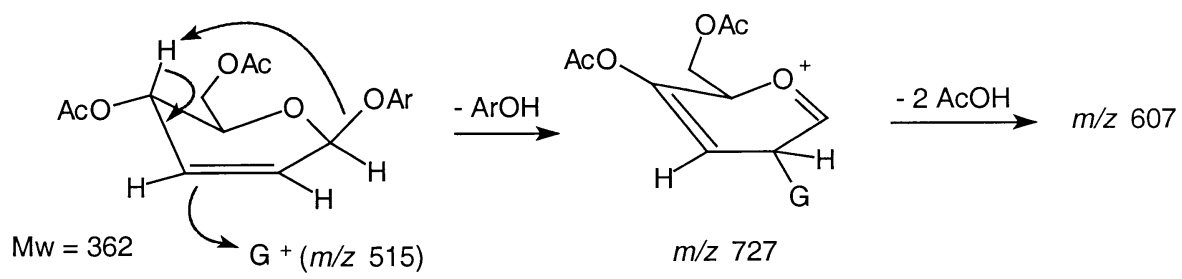

$\mathrm{Ar}=$ tert-butylphenol

Scheme 7. Quasi-concerted electrophilic attack of the covalent adduct ions at $m / z 515$ to the neutral arylglicoside concomitant with the tert-butylphenol elimination from the $\mathbf{2} \boldsymbol{\beta}$ anomer. 
Table 3. Percentage of the total ion current ${ }^{\mathrm{a}}$ of significant ions displayed in the CID spectra of the adduct ion at $m / z 455$ produced by isomers $1 \boldsymbol{\alpha}, \mathbf{2} \boldsymbol{\alpha}, \mathbf{2} \boldsymbol{\beta}$, and $3 \boldsymbol{\alpha}$ under self-ionization conditions (reaction time $=325 \mathrm{~ms}$; excitation time: top row: $3 \mathrm{~ms}$, italics: $6 \mathrm{~ms}$; tickle voltage $=0.5 \mathrm{~V}$ )

\begin{tabular}{|c|c|c|c|c|c|c|c|c|c|c|}
\hline \multirow{2}{*}{$\begin{array}{l}\text { Isomeric } \\
\text { compounds }\end{array}$} & \multicolumn{5}{|c|}{ Ion-molecule product ions (Th) } & \multicolumn{5}{|c|}{ Fragment ions (Th) } \\
\hline & 607 & 515 & 497 & 437 & 455 & 395 & 377 & 335 & 213 & 153 \\
\hline \multirow[t]{2}{*}{$1 \alpha$} & 0.4 & 1.3 & $<0.1$ & 0.7 & 56.7 & 12.7 & 1.3 & 2.7 & 12.5 & 5.8 \\
\hline & 0.3 & 2.6 & 0.3 & 1.1 & 43.1 & 18.3 & 2.3 & 2.8 & 18.6 & 6.5 \\
\hline \multirow[t]{2}{*}{$2 \alpha$} & 5.6 & 11.4 & 2.3 & 1.4 & 62.9 & 4.0 & 0.2 & 0.3 & 5.1 & 1.1 \\
\hline & 5.5 & 9.9 & 2.7 & 1.9 & 40.5 & 15.9 & 0.7 & 3.4 & 10.4 & 1.8 \\
\hline \multirow[t]{2}{*}{$2 \boldsymbol{\beta}$} & 7.2 & 8.5 & 1.5 & 1.5 & 59.4 & 2.2 & $<0.1$ & 0.3 & 3.3 & 0.5 \\
\hline & 5.1 & 6.6 & 2.3 & 2.8 & 25.6 & 21.3 & 1.2 & 5.1 & 8.5 & 2.5 \\
\hline \multirow[t]{2}{*}{$3 \alpha$} & 3.9 & 3.4 & 0.7 & 1.2 & 40.9 & 29.1 & 0.9 & 9.6 & 3.9 & 1.3 \\
\hline & 4.2 & 2.2 & 0.6 & 0.8 & 50.3 & 26.1 & 1.3 & 5.6 & 4.5 & 1.2 \\
\hline
\end{tabular}

${ }^{\mathrm{a} C}$ Calculated as: $100 \times$ ion intensity $/ \Sigma$ intensity (all sample ions).

tional ions at $m / z 213$ and $m / z 153$ are formed in the CID spectra produced by all the isomers. Even if their abundances are higher than those observed by dissociation of the species at $m / z 515$, they are comparable to those characterizing the self-ionization mass spectra. On the other hand, their relative abundances seem to be dependent upon a "memory effect" of the structure of the intact molecule, although the distinctive group which carries the structural differentiation is lost in the formation of these fragment ions; (3) the behavior that characterizes the positional isomers ortho $\mathbf{1} \boldsymbol{\alpha}$, meta $\mathbf{2} \boldsymbol{\alpha}$, and para $3 \boldsymbol{\alpha}$ show significant and large differences in the abundances of both adduct and fragment ions (Table 3). Minor differences can be noted for the two $2 \boldsymbol{\alpha}$ and $2 \boldsymbol{\beta}$ anomers. On the other hand, the comparison of the adduct ion/parent ion ratios produced at different reaction times under CID conditions of the ions at $\mathrm{m} / \mathrm{z}$ 455 prepared under SI conditions shows a significant differentiation of these anomers (Figure 3). Both of them produce adduct ions whose amount is almost exponential with the reaction time applied $\left(R^{2}>0.99\right)$. The stereochemical differentiation is clear, with the $2 \boldsymbol{\beta}$ anomer showing a much higher reactivity than $2 \boldsymbol{\alpha}$ by

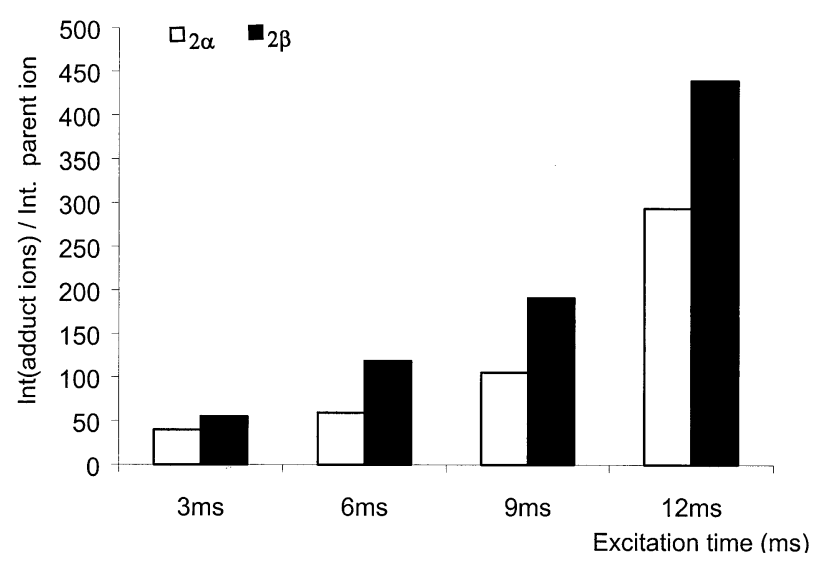

Figure 3. Adduct ion/parent ion ratios produced under low energy CID regime of the ions at $m / z 455$ prepared under SI conditions from $2 \boldsymbol{\alpha}$ and $2 \boldsymbol{\beta}$ anomers. The values obtained for different reaction time are reported. producing much more abundant adduct ions as well as fragment ions (data not shown).

Enhanced Self-Ionization Promoted by MassSelected Ion Molecule Reactions of the $2 \boldsymbol{\alpha}$ and $\mathbf{2} \boldsymbol{\beta}$ Anomers

It is noteworthy that while the fragment ion at $m / z 111$ constitutes the most abundant ionic species in the EI mass spectra, it disappears under self-ionization conditions. Aimed at investigating this phenomenon, we have studied the reactivity of the ion at $m / z 111$ towards the neutrals $2 \boldsymbol{\alpha}$ and $2 \boldsymbol{\beta}$.

The EI fragment ion can be mass-selected, and after variation of a delay time (i.e., reaction time duration) prior to application of the analytical scan step, its gas phase reactivity towards an introduced substrate can be studied.

It results that the ion at $m / z 111$ is being consumed by reactions with the neutrals yielding as a final product the species at $\mathrm{m} / \mathrm{z} 213$ that, even for reaction time of 300 $\mathrm{ms}$, is the most intense ion. Other ions are at $m / z 153$, produced by decompositions of the species at $\mathrm{m} / \mathrm{z} 213$ (see above), and an ion at $\mathrm{m} / \mathrm{z} 323$.

The species at $\mathrm{m} / \mathrm{z} 213$ can be produced by an electrophilic attack of the mass selected ion at $m / z 111$ to the neutral arylglycoside with the elimination of a neutral deacetylated glycoside (Scheme 8).

The reactivity of the ion at $m / z 111$ towards the two anomers $2 \boldsymbol{\alpha}$ and $2 \boldsymbol{\beta}$ is spectacularly different. Also, in this case the $\mathbf{2} \boldsymbol{\beta}$ anomer shows a much more pronounced reactivity than $2 \boldsymbol{\alpha}$. In fact, while a reaction time of $30 \mathrm{~ms}$ is required by $\mathbf{2} \boldsymbol{\beta}$ for producing equimolar quantities of the ions at $\mathrm{m} / \mathrm{z} 111$ and 213, in the case of $2 \boldsymbol{\alpha}$ the same ratio is obtained with a reaction time of 105 ms (Figure 4).

\section{Conclusions}

Different mass spectrometry techniques based on selfionization have been used to structurally characterize and differentiate positional and stereo isomers of a new 


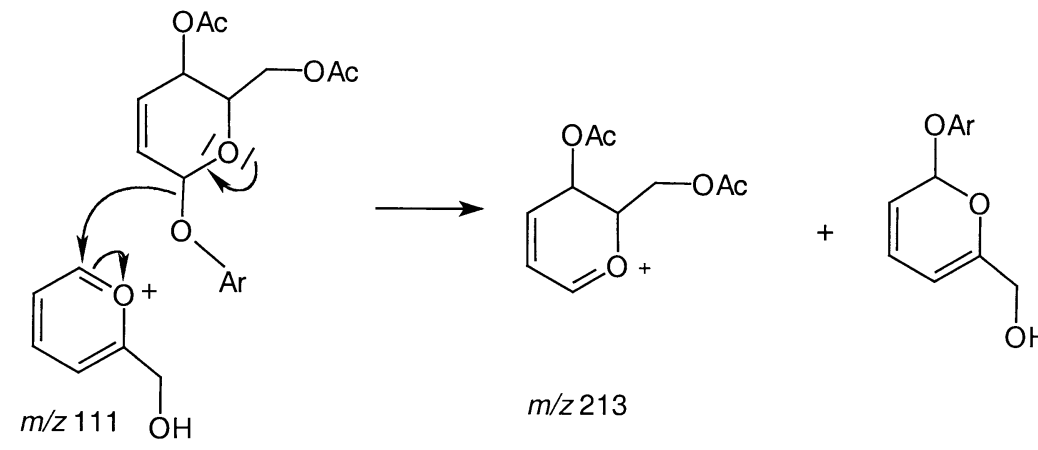

Ar=tert-butylphenol

Scheme 8. Electrophilic attack of the mass selected ion at $m / z 111$ to the neutral arylglycoside with the elimination of a neutral deacetylated glycoside.

class of arylglycosides having potential antioxidant activity. This has allowed to evidence the formation of diagnostic and stereoselective ions occurring under self-ionization via bimolecular processes. Even if some fragment ions have lost the stereochemistry in their structure, their formation and relative abundance are related to the initial structure of the parent neutrals.

Collision-induced dissociation experiments, carried out on ions formed by ion-molecule reactions, have revealed a strong reactivity of fragment ions towards neutrals (intact molecules or fragment neutrals) as well as dissociation. The CID spectra also show the existence of composite structures, i.e., cyclic and open-ring, for adduct ions at $\mathrm{m} / \mathrm{z} 515$ containing the
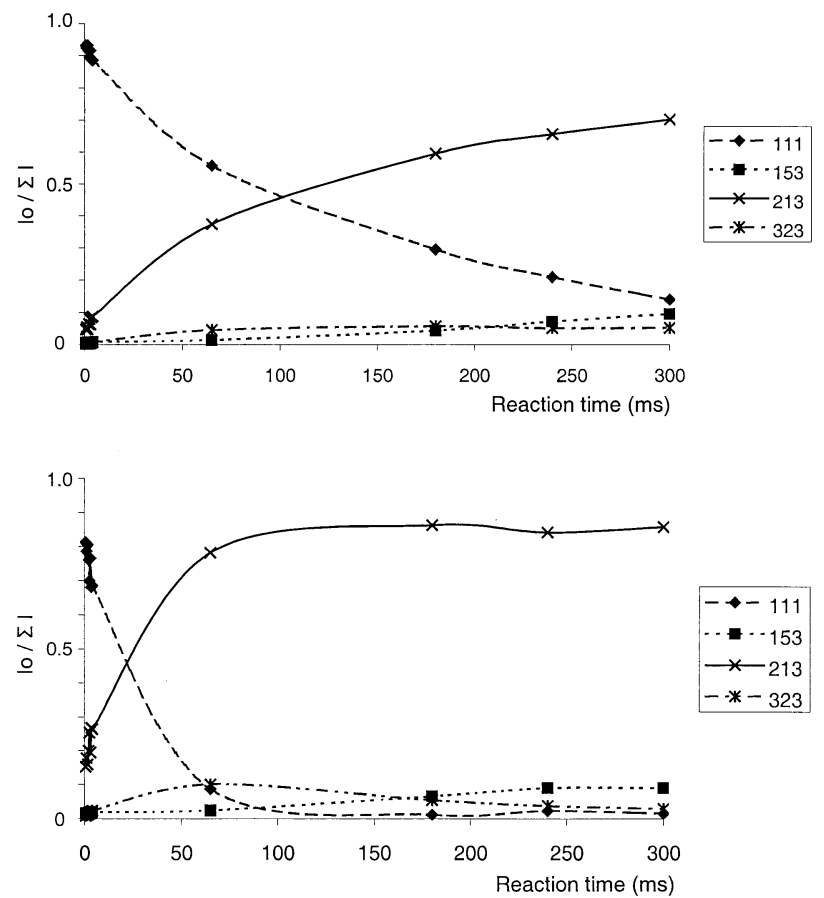

Figure 4. Variation of relative abundances of the product ions from ion-molecule reactions induced by the $\mathrm{m} / \mathrm{z} 111$ reagent ion upon different reaction times with the $2 \boldsymbol{\alpha}$ (top) and $\mathbf{2} \boldsymbol{\beta}$ (bottom) anomers. sugar moiety. These data show that the production of the adduct ions takes place according to a trans electrophilic approach which occurs on the double bond at the opposite side of the large anomeric groups. This orientation allows a cis 1-3 elimination of the $\mathrm{H}-/ \mathrm{CH}_{3} \mathrm{COO}$ - groups since they have a diaxial configuration. This kind of experiments revealed to be a suitable and powerful tool in isomeric differentiation and showed the utility of ion trap mass spectrometry in stereochemistry.

The study of mass-selected ion-molecule reactions and their kinetics has allowed to further differentiate the two $2 \boldsymbol{\alpha}$ and $2 \boldsymbol{\beta}$ anomers on the base of their different reactivity towards the selected ion at $m / z 111$.

\section{Acknowledgments}

GG thanks the Italian Consiglio Nazionale delle Ricerche for a fellowship in the NATO Senior Fellowships Program 2000. JCT thanks UPMC and CNRS for supporting this program and also the Varian company for the QISMS software.

\section{References}

1. Budzikiewicz, H.; Djerassi, C.; Williams, D. H. Structural Elucidation of Natural Products by Mass Spectrometry. HoldenDay: San Francisco, 1967.

2. Djerassi, C. Recent Advances in the Mass Spectrometry of Steroids. Pure Appl. Chem. 1978, 50, 171-184.

3. Green, M. M. Mass Spectrometry and the Stereochemistry of Organic Molecules. Top. Stereochem. 1976, 9, 35-110.

4. Mandelbaum, A. Applications of Mass Spectrometry to Stereochemical Problems. In Handbook of Stereochemistry, Vol. I; Kagan, H.; Thieme, G., Eds.; Stuttgart, 1977; pp. 137-180.

5. Giorgi, G.; Ponticelli, F.; Czira, G.; Vékey, K. Characterization and Differentiation of Heterocyclic Isomers. Tandem Mass Spectrometry and Molecular Orbital Calculations on 3-Methylisoxazolo- and 2-Methyloxazolopyridines. J. Am. Soc. Mass Spectrom. 1995, 6, 962-971.

6. Giorgi, G.; Anzini, M.; Cappelli, A.; Corelli, F.; Vomero, S. Characterization and Differentiation of Heterocyclic Isomers. Part 2. Mass Spectrometry and Molecular Orbital Calculations on Pyrrolo[1,2-a][1,4] benzodiazepin-4-one, -6-one, -4,6-dione. J. Am. Soc. Mass Spectrom. 1996, 7, 653-663. 
7. Rathahao, E.; Perlat, M. C.; Fournier, F.; Tabet, J. C. Stereochemical Effects Enhanced by Using Selective "Self-Ionization" Under Electron Ionization Conditions in a Quadrupole Ion Trap Mass Spectrometer. Int. J. Mass Spectrom. 1999, 193, 161-179.

8. Mandelbaum, A. Stereochemical Effects in Mass Spectrometry. Mass Spectrom. Rev. 1983, 2, 223-284.

9. Splitter, J. S.; Turecek, F. Applications of Mass Spectrometry to Organic Stereochemistry. VCH: New York, 1994.

10. Harrison, A. G. Chemical Ionization Mass Spectrometry; 2nd ed. CRC Press: Boca Raton, 1992

11. Winkler, F. J.; Stahl, D. Intramolecular Ion Solvation Effects on Gas-Phase Acidities and Basicities. A New Stereochemical Probe in Mass Spectrometry. J. Am. Chem. Soc. 1979, 101, 3685-3687.

12. Bastard, J. Do Khac; Manh, D.; Fetizon, M.; Tabet, J. C.; Fraisse, D. Ion-Molecule Reactions in the Gas-Phase. Part 1. Stereospecific Nucleophilic Substitution of Tertiary Alcohols by Ammonia. J. Chem. Soc. Perkin Trans. 2 1981, 1591-1595.

13. Olson, E. S.; Diehl, J. W. Serially Interfaced Gas Chromatography/Fourier Transform Infrared Spectrometer/Ion Trap Mass Spectrometer System. Anal. Chem. 1987, 59, 443-448.

14. Louris, J. N.; Cooks, R. G.; Syka, J. E. P.; Kelley, P. E.; Stafford, G. C.; Todd, J. F. J. Instrumentation, Applications, and Energy Deposition in Quadrupole Ion-Trap Tandem Mass Spectrometry. Anal. Chem. 1987, 59, 1677-1685.

15. Eichelberger, J. W.; Budde, W. L.; Slivon, L. E. Existence of Self Chemical Ionization in the Ion Trap Detector. Anal. Chem. 1987, 59, 2730-2732.

16. Pannell, L. K.; Pu, Q. L.; Fales, H. M.; Mason, R. T.; Stephenson, J. L. Intermolecular Processes in the Ion Trap Mass Spectrometer. Anal. Chem. 1989, 61, 2500-2503.

17. McLuckey, S. A.; Glish, G. L.; Asano, K. G.; Van Berkel, G. J. Self Chemical Ionization in an Ion Trap Mass Spectrometer. Anal. Chem. 1988, 60, 2312-2314.

18. Grela, K.; Konopski, L. Origin of $[\mathrm{M}+\mathrm{H}]^{+}$Ions in Electron Impact Mass Spectra of Tertiary Nitrosonitriles. J. Mass Spectrom. 1995, 30, 1441-1446.

19. Méchin, N.; Plomley, J.; March, R. E.; Blasco, T.; Tabet, J. C. Formation of Protonated Phosphonates in the Ion-Trap Mass Spectrometer Under Electron Impact Conditions. Rapid Commun. Mass Spectrom. 1995, 9, 5-8.
20. Varki, A. Biological Roles of Oligosaccharides: All of the Theories are Correct. Glycobiology 1993, 3, 97-130.

21. Kennedy, J. F. Carbohydrate Chemistry. Oxford University Press: New York, 1988.

22. Ikan, R. Naturally Occurring Glycosides. J. Wiley and Son: New York, 1999.

23. Gaucher, S. P.; Leary, J. A. Determining Anomericity of the Glycosidic Bond in Zn(II)-Diethylenetriamine-Disaccharide Complexes Using $\mathrm{MS}^{\mathrm{n}}$ in a Quadrupole Ion Trap. J. Am. Soc. Mass Spectrom. 1999, 10, 269-272.

24. Asam, M. R.; Glish, G. L. Tandem Mass Spectrometry of Alkali Cationized Polysaccharides in a Quadrupole Ion Trap. J. Am. Soc. Mass Spectrom. 1997, 8, 987-995.

25. Mendonca, S.; Cole, R. B.; Zhu, J.; Cai, Y.; French, A. D.; Johnson, G. P.; Laine, R. A. Incremented Alkyl Derivatives Enhance Collision Induced Glycosidic Bond Cleavage in Mass Spectrometry of Disaccharides. J. Am. Soc. Mass Spectrom. 2003, $14,63-78$

26. Domon, B.; Costello, C. E. A Systematic Nomenclature for Carbohydrate Fragmentations in FABMS/MS of Glycoconjugates. Glycoconj. J. 1988, 5, 397-409.

27. Sims, R. J.; Fioriti, J. A. In CRC Handbook of Food Additives, 2nd ed., Vol. II. Furia, T. E., Ed.; CRC Press: Boca Raton, 1980; p 13.

28. Pessina, F.; Kalfin, R.; Esposito, L.; Fusi, F.; Valoti, M.; Ponticelli, F.; Sgaragli, G. P. Neuroprotection Afforded by Some Hindered Phenols and Alpha-Tocopherol in Guinea-Pig Detrusor Subjected to Anoxia-Glucopenia and Reperfusion-Like Conditions. N-S Arch. Pharm. 2001, 364, 462-471, and references cited therein.

29. Ponticelli, F.; Trendafilova, A.; Valoti, M.; Saponara, S.; Sgaragli, G. P. Synthesis and Antiperoxidant Activity of New Phenolic O-Glycosides. Carbohydr. Res. 2001, 330, 459-468.

30. Giorgi, G.; Ponticelli, F.; Salvini, L.; Trendafilova, A.; Valoti, M.; Pessina, F. Synthetic Approach, Regio and Stereochemical Characterization and Differentiation of New Potential Antioxidant $C$ - and O-Arylglycosides. Eur. J. Org. Chem. 2003, 106115.

31. March, R. E.; Todd, J. F. J. Practical Aspects of Ion Trap Mass Spectrometry; Vols. I-III; CRC Press: Boca Raton, 1995.

32. Hunter, E. P. L.; Lias, S. G. Evaluated Gas Phase Basicity and Proton Affinities of Molecules: An Update. J. Phys. Chem. Ref. Data 1998, 17, 413-656. 